\title{
Auditors' Usage of Computer-Assisted Audit Techniques (CAATs): Challenges and Opportunities
}

\author{
Raed Jameel Jaber \\ Zarqa University, Jordan \\ raedjaber125@yahoo.com \\ Rami Mohammad Abu Wadi \\ Ahlia University, Manama, Kingdom of Bahrain \\ rwadi@ahlia.edu.bh
}

\begin{abstract}
The objectives of this research is to give a clear view of the electronic auditing environment in companies, to determine the main benefits and challenges of ComputerAssisted Audit Techniques (CAATs) and to review the opinions of researchers on Generalized Audit Software (GAS). The study also sheds the light on the reality of electronic auditing in Kingdom of Bahrain. The descriptive approach was used, where the previous studies were surveyed, discussed accurately, and then the results of the study were reached. The results showed the benefits and challenges of evolving from traditional audit techniques to CAATs. This research provides more detailed information about the use of GAS in the different sectors of companies. It also provides academic contribution not only in auditing area but also in information technology, especially in Bahrain. At the end of the study, there are suggestions for future research, which may help to get a qualitative achievement in the use of electronic audit and CAATs in Bahrain.
\end{abstract}

Keywords: Computer-Assisted Audit Techniques (CAATs), Generalized Audit Software (GAS), Auditor, Computer, Audit Quality.

\section{Introduction}

The endless shifts in the world of business are allegedly impacted by the current technology and information revolution. Computer-based tasks have successfully replaced paper-based tasks in the majority of today's business organizations. Auditing is one of the sectors that witnessed massive shifts. Paper-based auditing has also been replaced by computer-based auditing. However, it still exists and is used by some firms.

It is assured that to enable auditors issue high_quality accounting data as well as making simultaneous decisions, it is important to have and rely on quality data in addition to exist on_lin. Researchers in this domain assure that real_time data is essential for accuracy of outcomes in the auditing domain. When auditors obtain electronic data, they can handle it in a more flexible manner (Chang, et al., 2008). This data is certainly accessible; transferable; is simply reserved, condensed, and organized in a manner better than the paper-based accounting data. Writers in the auditing domain suggested that Information technologies drive firms to do their transactions in an electronica manner. They will be able to issue their financial statements electronically and on_line through real_ time system. At the most recent times and under the umbrella of the real _time accounting (RTA) systems, it is possible that financial data is processed electronically as well as having audit evidence available in an electronic form. This required from firms to replace their paper and traditional documents with electronic ones including orders for purchasing; invoices; and checks (Rezaee et al., 2001).

The change in business process that removes a traditional source of information requires the creation of new audit procedures to conduct financial audit. The primary objective of financial audit and generally accepted 
auditing standards (GAAS) does not change because all or a part of the client's records are in electronic form (Hanes, et al., 2013).

Auditing Practice Regulation 1009 "Computer-Assisted Audit Techniques"(CAATs) is developed based on the International Auditing Practice Regulation IASP. "Computer Assisted Audit Techniques" was approved by the International Federation of Accountants (IFAC) in the 2001 edition (Ciprian-Costel, M., 2014). Auditing firms and auditing specialists have actually introduced numerous CAATs. Such techniques have been improved to aid auditors in carrying out their auditing works depending on computerized accountancy information. The concept of computerized accounting information systems has found its way into the world of accounting as a result. It has been mentioned that one of the most significant and widely employed CAATs in electronic auditing is Generalized Audit Software which is abbreviated as (GAS) (Singleton, 2006). GAS is used by auditors to analyze and audit either live or extracted data from a wide range of applications (Debreceny et al., 2005).

The modern computerized environment, in which any audited entity operates nowadays, creates new opportunities, but also new risks, additional rules regarding security accuracy and acceptable error rates, thus constantly influencing the auditors' work (Ciprian-Costel, M., 2014). On the other hand, previous studies have shown many of the benefits of electronic auditing, especially with increasing of computerized accounting systems such as ERP (Enterprise Resource Planning) and the large volume of accounting transactions. Therefore, this research focuses on the use of Computerized Assisted Audit Techniques (CAATs) in the audit of companies.

This research assumes that the implementation of CAATs by the auditor will provide a positive influence on transparency, audit quality and accountability of financial statements of companies. Research about the use of CAATs and GAS is very limited. Therefore, to find a reference regarding factors related to the use of CAATs or GAS, this research reviews the literature of information system in auditing.

The following section will talk about the audit environment in the Kingdom of Bahrain and the extent of interest in using Computer - Assisted audit techniques in auditing process. The rest of the paper will discuss the key findings with reference to prior literature. The conclusion and suggestion for future research are discussed further.

\subsection{Research Objectives:}

The main objective of this research is to give a clear picture of the electronic auditing environment in companies. The researchers aimed to determine the main benefits achieved by both internal and external auditors from the usage of CAATs. The researchers conducted a review of previous studies on GAS which is one of the most important of these audit techniques. Also, the researchers reviewed the practical reality of using the electronic tools of auditing in Bahrain

\subsection{The contributions of the study:}

This research makes two contributions to the literature:

1) This research contributes academically by providing comprehensive illustration of the utilization of CAATs and GAS by the auditor of the company in creating transparency, audit quality and accountability. Also, the study reviews the positive and negative opinions of researchers on the application of GAS in the company.

2) This research gives a clear indication of the importance of electronic auditing in emerging economies such as Bahrain. The scarcity of previous studies on E-audit in Bahrain is might be due to the low number of audit failures. Since the establishment of the first shareholding companies 
until 2008, there were only three reported cases of audit failure (Al-Ajmi, 2009). Consequently, this study investigates the use of electronic auditing techniques in Bahraini audit environment, while previous studies searched on other issues in auditing; such as corporate governance, independence and audit quality. Hence, this study provides additional insights to E- audit in Bahrain.

\section{Literature Review}

\subsection{Audit and Information Technology in Bahrain}

The audit in Bahrain is much respected profession like other parts of the world. Many audit firms are operating in Bahrain including all Big 4; The Big Four accounting firms refer to Deloitte \& Touche (D\&T), PricewaterhouseCoopers (PwC), KPMG, and Ernst \& Young. The audit firms are specialized in a number of services, such as external audit, internal audit, taxation, consultancy services, fraud examinations and legal services. In Bahrain, the main services offered by the audit firms are external auditing and internal auditing. External auditing is focusing on providing a reasonable assurance on the financial statements free from material misstatements and according to International Financial Reporting Standards (IFRSs).

Audit services in Bahrain are provided by 24 accounting firms. Five of these are considered local; four are operating as foreign branches; and the remaining are linked to international firms. The Big 4; have a strong presence in Bahrain Kingdom (Joshi, Al Ajmi \& Bremser, 2009).

A survey in Bahrain of 300 financial and credit analysts shows that they considered auditors' opinion useful. Both groups assume that the characteristics of Big-Four firms allow them to produce better-quality reports than non-Big firms (Al-Ajmi, 2009). Auditors in Bahrain indicated that the major process' problems are associated with the client's culture lack, access to information, evidence problems and poor accounting systems. All of these problems may ultimately lead to poor audit quality in Bahraini audit environment. (Joshi, Al Ajmi \& Bremser, 2009).

Audit services in Bahrain are regulated by the Amiri Decree (No. 26 of 1996). To register at the Auditors Registrar at the Ministry of Industry and Commerce Applicants must satisfy the following conditions: (1) "must being a Bahraini citizen (with the exception of members of internationally recognized accounting/auditing societies and holders of CA, CPA, or ACCA qualifications recognized by the relevant authorities)”. (2)“In accordance the law an auditing firm may be registered as a Partnership Company, a Branch of a Foreign Company or an Individual Establishment (sole proprietorship)". (http://www.moic.gov.bh)

The Central Bank of Bahrain (CBB) requires financial institutions to be audited by one of the big audit firms. It is also required from audit firms to get two licenses, the first to practice auditing and the second to offer auditing services to financial institutions. Auditors who are specialized licensees must be independent. Auditors who are resigned or removed from their tasks are required to inform the CBB of the reasons for the termination of their appointment. In Bahrain, it is not mandatory to switch audit firms, but experience has shown that switching of audit firms in many cases only after audit failure. The CBB requires auditors of financial institutions to switch auditing partners at least every five years. (Said and Khasharmeh, 2014)

On the other hand, the CBB requires commercial banks to appoint a specialized consulting firm for auditing on the electronic banking system, in order to expose the existing gaps and weaknesses in the system. If any such gaps found it can penetrate the data of customers, which may cause cases of fraud .The Central Bank is taking voluntary measures towards the violator banks. The bank should conduct the E-audit every six months, twice a year, and the auditor must be independent. We must clarify the meaning of the electronic auditing. It is the 
process of applying any sort of operating system by using information technology to assist the auditor in planning, control and documentation of the audit. (Thomas, Henki, 2009)

The Information Systems Audit and Control Association (ISACA), Bahrain branch, was established in Bahrain in October 2010; to enhance the role of information technology and security. Bahrain is a developed financial center in the Middle East region and relies heavily on IT in various financial transactions. The Bahraini branch of ISACA has a number of qualified human resources that will contribute to raising awareness of the importance of information systems in the Kingdom of Bahrain. It offers to its members some professional and specialized certificates in auditing, security of information systems and governance.

On the other hand, the internal auditing in Bahrain focuses on operations, internal controls, policies and procedures, corporate governance, risk management and compliance with laws, regulations and by-laws. Furthermore, the internal auditor is responsible to assess the internal controls of the audit and report to the client, whether there are effective internal controls to detect or prevent frauds and errors. The cost of these services may differ from one audit firm to another, depending on a number of factors, such as the size of the client, the number of transactions per year and the nature of the client business.

Banks use different ratings for the audit firms in Bahrain. This ranking influences on the amount that will be lending to a client. For example, KPMG Fakhro has "A" rating, and if a company provided the bank with an unqualified audit report from KPMG Fakhro, then the bank will lend the highest loan amount to the client. In contrary, if a client provided an audit report from an audit firm with a low rating, the client may even not get a loan or get lower amount of loan from the bank.

The audit market in Bahrain has special characteristics. It is characterized by dominance of few auditing firms; the Big Four, largely uncommon cases of switching audit firms, weak enforcement of regulation reverent to audit industry; with exception of those related to financial institutions ( Al-Ajmi,2009) .

Most of the companies in Bahrain are from Small and Medium Enterprises (SMEs). From April 2014, Bahrain and other Gulf Cooperation Council (GCC) countries are facing difficulties of budget deficiency due to the decrease in the prices of oil. The GCC economies are encouraging the market to save more rather than spending. GCC governments are trying to diversify their economic activities such as manufacturing, tourism, financial services and Information and Communication Technology (ICT) services and others. That's the reason, that companies in Bahrain and other GCC are more focusing on the external auditing, rather than any other services. The other reason of external auditing is its mandatory requirement as per the law. Further, this is because the audited financial statements are a requirement for many services, such as getting a loan from the bank, renewing the commercial registration, in addition to others. This fact can be reflected in the revenues of audit firms, as it generates the highest revenue from external audit among all the services provided.

Alqatanani and Hezabr (2015) surveyed a sample of 40 audit firms in Kingdom of Bahrain; to measure the extent of recognizing the auditing strategies in light of information technology. The most important findings of the study were: There is a Lack of sufficient level of awareness among auditors in Bahrain on auditing strategies and electronic audit, the level of using of information technology is low in various fields, the lack of financial resources and software needed to implement the electronic audits, the lack of appropriate level of scientific and practical training of staff to audit in the light of information technology, the lack of confidence in electronic procedures, fear of data loss and the inability to maintain data protection. In addition, there is a belief that the expansion through the use of information technology will lead to the downsizing of some employees.

\subsection{Background of Electronic Audit}


The auditing sector has always been perceived as a sector that exceeds being complicated. It is a sector that full of challenges. The auditing profession is one of the numerous domains that got impacted by the advances that took place in the entire world due to the technological and information revolution. Paper-based auditing became something of the past though there are auditing firms that still implement it. At the same time, paper-based auditing was quite replaced by electronic auditing. Electronic auditing has been referred to as "Computerassisted auditing, where electronic records are used to complete all or part of the audit" (Florida Department of Revenue, 2002).

Technologies that do merely exist about twenty-five years ago have already gained power after being amended .These tools are now able to hide general mismanagement and fraudulent practices in an unbelievable that is completely different from the old-school auditors. Fortunately, technology managed to make use of some new trends in the auditor's quiver. Such trends have been found to be used in a particular manner. One of the most significant advantages for e-auditing is facilitating the processes of the confirmations that were considered by auditors as problematic and time-consuming issues. These issues are considered as more difficult, particularly; when there some kind of misuse which may leads to fraudulent practices (Sheridan, 2014). Unlike computerbased auditing, paper-based editing has various disadvantages. Human intervention in the sequences of the activities is one of the most prominent disadvantages that has been given due attention by reviewers in this domain (Solieri and Hodowanitz, 2016).

Literature shows that there are numerous computer-based auditing instruments and techniques that were introduced have been developed to aid auditors while doing their audits on computerized accountancy data. One of the most widely implemented software tools is known as generalized audit software (GAS) (Singleton, 2006). This software which is referred to as "GAS" is implemented by auditors to analyze and audit the data they have; whether they are categorized as live data or extracted data from a wide array of applications (Debreceny et al., 2005). GAS has been referred to as that data extraction or data analysis software that was made up to carry out particular audit procedures and statistical analyses.

The functions of this software include browsing, analyzing, categorizing, summarizing, stratifying, sampling and implementing calculations. In spite of the fact that the majority of audits do currently apply electronic audit procedures on their audit work, the core processes of audit are not usually adopted without the automation offered by GAS. Nevertheless, auditors still tend to apply some of the most traditional auditing procedures while composing their own audit points of view depending on a sample of accounting transactions instead of investigating all the available data.

To illustrate the differences between CAATs and GAS, Braun and Davis defined CAATs as "any use of technology to assist in the completion of an audit". Based on this definition, there are various types of CAATs, ranging from word processing or electronic spreadsheets to expert system (Debreceny, Lee and Toh, 2005). Moreover, CAATs used by external and internal auditor can be grouped into electronic audit working paper, fraud detection, generalized audit software (GAS), and continuous monitoring (Mahzan \& Lymer, 2014). So that, we can say that GAS is one type of CAATs that helps auditor to do data extraction, data query, data summary, data analysis (Ahmi \& Kent, 2012). GAS is divided into two types which are commercially available software and internally developed software (Widuri, Connell and Yapa, 2016).

\subsection{Benefits of E-Auditing:}

It is nature of the records of the firms that makes auditors take the decision of whether or not; e-auditing is going to be applied instead of paper-based audit. There are numerous benefits that the firms harvest from the implementation of the e-audit. It is probable that electronic audits can minimize the overall endeavors exerted by the clients as well as the audit department to complete the audit. When the time required to fulfill the auditing processes is short, cost savings do directly exist. There are various examples in which, procedures that provide 
detailed audit are likely to be performed through electronic data in the same duration taken to audit a sample of paper documents.

Among the advantages of using the Computer-Assisted Audit Techniques (CAATs), we include:

1) Testing the client's accounting software, as the auditor can verify whether it works correctly or not. Hence, the auditor can test the accounting program and its records directly at their origin, rather than testing paper documents that are supposed to be accurate replicas.

2) Testing of large volumes of data in a short time and with good accuracy. When the auditor uses CAATs, he will be more confidence in his opinion.

3) Cost effectiveness because, once an audit software is implemented, it can be used year after year to obtain audit evidence.

4) CAATs can help in the transparency of financial reports within organizations because they are tools where fraudulent and misappropriated practices are easily detected (Olasanmi, 2013)

The auditor should make comparisons between the results obtained using computer-assisted techniques and the results of traditional tests. If similar results are obtained, the auditor's general confidence will grow. (CiprianCostel, M., 2014)

\section{Audit Quality and CAATs:}

Audit quality is a concept that has different definitions for different researches. DeAngelo (1981) hypothesizes a two-dimensional definition of audit quality: First, a material misstatement must be detected, and second, the material misstatement must be reported. Consequently, Titman and Trueman (1986) propose that a good auditor provides precise information regarding the firm's value. Audit quality is defined as the probability that financial statements contain no material misstatements (Palmrose, 1988). While Davidson and Neu (1993) define audit quality as the ability of the auditor to detect and eliminate material misstatements and manipulations in the net income reported.

We can say that audit quality is the increasing function of the ability of an auditor to detect accounting misstatements and it is related to the degree of auditor independence. Here, the following question arises: Should the auditor use Computer-Assisted Audit Techniques (CAATs) to improve the audit quality?

Users of financial statements perceive audit reports to provide absolute assurance that company's financial statements have no material misstatements and do not perpetrate fraud (Epstein \& Geiger, 1994). However, auditors perceive audit reports to provide a reasonable assurance in terms of strict adherence to International Accounting Standards (IASs) requirements.

Previous studies show that auditor should utilize technology for audit process (DeAngelo, 1981) because it can increase effectiveness and efficiency in making decision for audit (Janvrin, Bierstaker, and Lowe, 2008). Moreover, the use of technology by auditor can increase the quality of audit procedure and the quality of audit result (Manson, McCartney, Sherer, and Wallace, 1998).

A study conducted by Ahmi, Aidi and Kent, Simon (2012) was originally intended to explore the level of implementation of the external auditors in the UK for the GAS as an audit software on SMEs in the UK. Data statistical analysis showed that the implementation of GAS is not common in between UK auditors as seventy three auditors reported their rejection for implementing GAS as they find it is not that beneficial for their auditing clients. The benefits of the GAS implementation were confronted by its high cost.

Another study by Vasarhelyi and Romero, (2014) found that integrating technology support teams with auditors is a process that leads to improving usability in addition to maximizing adoption of technologies in auditing. The main results of (Omonuk and Oni, 2015) showed that there is a positive relationship between the use of CAATS 
and audit quality in Nigeria. Also, the study explained that local Nigerian firms are not effective in applying CAATs, and do not produce quality audit reports. The purpose of the study of Eni , (2016) is to present and discuss the most recent concepts in auditing which is "the online collaborative audit system". Data analysis guided the researchers to introduce the online collaborative audit system which was defined by the researcher as "An inter-organizational system that employs the techniques of collaborative intelligence between the stakeholders of the audit process within a particular area that is dependent on the Internet". Though carrying out an assessment of the system design, the researchers were able to predict that an online collaborative system is likely to implement.

\section{The Roles of Electronic Audit:}

As one of the most widely implemented audit software by audit firms GAS has been identified to enable auditors to find out the financial statements' misstatements whether or not, these misstatements are on purpose. This has been a great support for auditors to fulfill the overall audit objectives that include: verification of audit data, fulfillment, ownership, assessment, accuracy, categorization and disclosing the data produced via the accounting software (Debreceny et al., 2005). There are numerous packages of software included within GAS. These packages are: audit command language (ACL); IDEA; and ProAudit. Such packages of software are likely to permit auditors to interrogate various systems of accounting which guides auditors towards carrying out one hundred percent accurate, true, and fair data for their clients (Greenstein et al., 2008).

Making use of electronic audit and its software packages has been identified to be extremely beneficial and significant. Implementation of the electronic audit has been given due care and support by the auditing standards. The benefits of the electronic audit and the implemented software such as GAS have been reviewed in various occasions and studies. This software investigated and was found to be compliant with a lot of functions of CAATTs that actually stem from auditing standards that were introduced by the American Institute of Certified Public Accountants (AICPA) (Janvrin et al., 2009).

In one of the most well-reputed countries for their auditing firms such as the UK, it has been found that implementing electronic audit and making use of the audit software as GAS overwhelms the audit profession. This is attributed to the fact that there is a wide recognition for the numerous functionalities and benefits provided by GAS to auditors and audit firms. There are assertions that audit software firms such as Sage which is a world class audit software provider has already provided their audit software to a number of seven hundred and sixty thousand SMEs all over the UK. This is an apparent evidence for the global tendency to employ electronic audit instruments and software. This can also be thought of as an evidence supporting auditors' usage of electronic audit and $\backslash$ or adopt software as GAS.

\section{Conclusions and suggestions for Future Studies:}

\subsection{Conclusions:}

The following is the conclusion of this research:

- The main result of this paper is summarized by determining the benefits and challenges of evolving from traditional audit techniques to CAATs. In IT environments, the auditors would start using the tools of business intelligence, a key factor which contributes to making successful business decisions. CAATs enable auditors to test large amount of data quickly and accurately and therefore increase the confidence they have in their opinion. The findings of previous studies showed that CAATs have played a major role in fraud 
detection, transparency, audit quality and cost effectively. E-auditing is facilitating the processes of the confirmations that were considered by auditors as problematic and timeconsuming issues.

- This research provides more detailed information about the use of GAS in the different sectors of companies. This research was conducted by reviewing many previous studies. Despite GAS is a wellknown program in extracting data, analyzing, browsing, classification, sampling and computation; auditors still tend to apply some of the most traditional audit procedures with their audit points. Some auditors found that GAS is not beneficial for their auditing clients. The benefits of the GAS implementation were confronted by its high cost.

- External auditors are recommended to use Computer Assisted Audit Techniques particularly when the majority of the available financial information would be in an electronic form.

- The features of the audit team individuals and integrating technology support teams with auditors; are improving usability in addition to maximizing adoption of technologies in auditing.

- It is required from auditors to make better understanding of the standards of IT audit and their guidelines on carrying out an IT audit. Here, the auditors must focus on audit standards related to IT, as published by AICPA and ISACA.

- The researchers predicted that an online collaborative system is likely to be implement, which achieves many benefits for auditors.

- I think that the study was able to shed light on a certain part of the practical reality of electronic auditing in Bahrain.

\subsection{Suggestions for Future studies:}

This research provides opportunities for future research, which are:

1) Future research to measure the actual use of CAATs or GAS by the audit firms in Kingdom of Bahrain.

2) Future research could examine quantitatively to what extent inhibiting factors affect the intention of the auditors in Bahrain to use CAATs or GAS.

3) Future research could perform a model that links the quality of auditing as a dependent variable and the techniques of electronic auditing (CAATs) as an independent variable. This model can be tested quantitatively through an applied study of auditing companies in emerging economies as Bahrain. 


\section{References}

1. A. Vasarhelyi, M., \& Romero, S.: Technology in audit engagements: a case study. Managerial Auditing Journal, 29(4), 350-365 (2014).

2. Ahmi, A., \& Kent, S.: The utilisation of generalized audit software (GAS) by external auditors. Managerial Auditing Journal, 28(2), 88-113 (2012).

3. Al-Ajmi, J.: Audit firm, corporate governance, and audit quality: Evidence from Bahrain. Advances in accounting, 25(1), 64-74 (2009).

4. Ciprian-Costel, M.: Arguments On Using Computer-Assisted Audit Techniques (Caat) And Business Intelligence To Improve The Work Of The Financial Auditor. Management Strategies Journal, 26(4), 212-220 (2014)

5. Davidson, R. A., \& Neu, D.: A note on the association between audit firm size and audit quality. Contemporary Accounting Research, 9(2), 479-488 (1993)

6. DeAngelo, L. E. : Auditor size and audit quality. Journal of accounting and economics, 3(3), 183-199 (1981)

7. Debreceny, R., Lee, S. L., Neo, W., \& Shuling Toh, J.: Employing generalized audit software in the financial services sector: Challenges and opportunities. Managerial Auditing Journal, 20(6), 605-618 (2005)

8. Eni, L. C.: Considerations regarding the design of an online collaborative audit system. Managerial Auditing Journal, 31(1), 64-86 (2016)

9. Epstein, M. J., \& Geiger, M. A. : Investor views of audit assurance: Recent evidence of the e. Journal of accountancy, 177(1), 60 (1994)

10. Greenstein-Prosch, M., McKee., T. E., \& Quick, R. : A Comparison of the Information Technology Knowledge of United States and German Auditors, International Journal of Digital Accounting Research, 8(July), 45-79 (2008)

11. Hanes, D. R., Porco, B. M., \& Thibodeau, J. C.: Simply Soups Inc.: A Teaching Case Designed to Integrate the Electronic Cash Confirmation Process into the Auditing Curriculum. Issues in Accounting Education, 29(2), 349369 (2013)

12. Janvrin, D., Bierstaker, J., \& Lowe, D. J.: An examination of audit information technology use and perceived importance. Accounting Horizons, 22(1), 1-21 (2008)

13. Janvrin, D., Lowe, D. J., \& Bierstaker, J. : Auditor acceptance of computer-assisted audit techniques. Iowa State University, Arizona State University and Villanova University, 4 (2008)

14. Joshi, P. L., Al Ajmi, J., \& Bremser, W. G.: A study of auditor-client relationships and problems in the Bahraini audit environment. Advances in Accounting, 25(2), 266-277 (2009).

15. Mahzan, N., \& Lymer, A.: Examining the adoption of computer-assisted audit tools and techniques: Cases of generalized audit software use by internal auditors. Managerial Auditing Journal, 29(4), 327-349 (2014)

16. Manson, S., McCartney, S., Sherer, M., \& Wallace, W. A.: Audit Automation in the UK and the US: A Comparative Study. International Journal of Auditing, 2(3), 233-246 (1998).

17. Olasanmi, O. O: Computer aided audit techniques and fraud detection. Research Journal of finance and accounting, 4(5), 67-80 (2013)

18. Omonuk, J. B., \& Oni, A. A.: Computer Assisted Audit Techniques and Audit Quality in Developing Countries: Evidence from Nigeria. Journal of Internet Banking and Commerce, 20(3), 1 (2015)

19. Palmrose, Z. V.: 1987 Competitive Manuscript Co-Winner: An analysis of auditor litigation and audit service quality. Accounting review, 55-73 (1988)

20. Rezaee, Z., Elam, R., \& Sharbatoghlie, A.: Continuous auditing: the audit of the future. Managerial Auditing Journal, 16(3), 150-158 (2001)

21. Said, K., \& Khasharmeh, H.: Auditors' perceptions on impact of mandatory audit firm rotation on auditor independence-Evidence from Bahrain. Journal of Accounting and Taxation, 6(1), 1 (2014)

22. She-I Chang, Cheng-Chih Wu \& I-Cheng Chang : The Development of a Computer Auditing System Sufficient for Sarbanes-Oxley Section 404- A Study on the Purchasing and Expenditure Cycle of the ERP System, Information Systems Management, 25:3, 211-229 (2008) 
23. Thomas, William, Henki, Emerson : Review of Theory and Practice, translation and localization by Ahmed Haggag and Kamal-uddin Saeed, Mars Publishing House, Saudi Arabia, p. 436-438 (2009)

24. Titman, S., \& Trueman, B.: Information quality and the valuation of new issues. Journal of accounting and economics, 8(2), 159-172 (1986)

25. Widuri, R., O’Connell, B., \& Yapa, P. W.: Adopting generalized audit software: an Indonesian perspective. Managerial Auditing Journal, 31(8/9), 821-847 (2016). 